\title{
SMART METER-DRIVEN ESTIMATION OF RESIDENTIAL LOAD FLEXIBILITY
}

Document Version

Accepted author manuscript

Link to publication record in Manchester Research Explorer

\section{Citation for published version (APA):}

Ponocko, J., \& Milanovic, J. V. (2017). SMART METER-DRIVEN ESTIMATION OF RESIDENTIAL LOAD

FLEXIBILITY. In CIRED 2017

\section{Published in:}

CIRED 2017

\section{Citing this paper}

Please note that where the full-text provided on Manchester Research Explorer is the Author Accepted Manuscript or Proof version this may differ from the final Published version. If citing, it is advised that you check and use the publisher's definitive version.

\section{General rights}

Copyright and moral rights for the publications made accessible in the Research Explorer are retained by the authors and/or other copyright owners and it is a condition of accessing publications that users recognise and abide by the legal requirements associated with these rights.

\section{Takedown policy}

If you believe that this document breaches copyright please refer to the University of Manchester's Takedown Procedures [http://man.ac.uk/04Y6Bo] or contact uml.scholarlycommunications@manchester.ac.uk providing relevant details, so we can investigate your claim.

\section{OPEN ACCESS}




\section{SMART METER-DRIVEN ESTIMATION OF RESIDENTIAL LOAD FLEXIBILITY}

\author{
Jelena PONOĆKO \\ University of Manchester, UK \\ jelena.ponocko@manchester.ac.uk
}

\author{
Jovica V. MILANOVIĆ \\ University of Manchester, UK \\ milanovic@manchester.ac.uk
}

\begin{abstract}
This paper presents methodology for estimating load composition within forecasted active and reactive load in residential area. The methodology relies on the assumption that a certain part of the end-users supplied by the same bulk point are monitored with smart meters which have the ability to measure active load of each appliance every minute. The results demonstrate the effect of the percentage of end-users monitored by smart meters on the accuracy of decomposition of the aggregated demand.
\end{abstract}

\section{INTRODUCTION}

With the evolution of smart grids and liberal electricity markets, demand response (DR) has been recognized as one of the more economic solutions for operating the power network [1]. The traditional load monitoring systems (electricity meters) have become obsolete for the demand side management (DSM) requirements. The rollout of smart metering systems in residential areas around the world will enable better observability of the end-users' behavior and their potential to participate in network daily operation.

The effectiveness of DSM actions largely depends on the flexibility of the demand side. Load flexibility, or the size of deferrable/curtailable loads, depends on the load composition. Until now, mostly large industrial users have been included in DR programs [2]. On the other hand, there is a significant, yet mainly untapped potential for DR in residential area. Taking the UK as an example, residential (domestic) sector is the largest final user of electrical energy, accounting for around $30 \%$ of overall consumption [3]. As the installation of smart meters (SMs) ultimately depends on the end-users' agreement, there will be only part of the consumption with higher observability in the future distribution grid. It was reported in [4] that around 50\% of households would like a SM installed, $25 \%$ did not want a SM and the remainder was undecided. Therefore, there is a need to assess the level of flexibility that could be expected from the demand considering its limited observability, based on the available number of smart meters in an aggregation of end-users.

Estimation of load flexibility can be done by assessing the size of controllable load within the total load. Furthermore, load can be disaggregated (decomposed) into load categories, such as resistive loads, induction motors, lighting, etc. in order to obtain a more detailed insight into the types of load utilized on a daily or seasonal basis.

This paper presents methodology for short-term forecasting (up to day-ahead) of load composition at aggregation level. It investigates the accuracy of load disaggregation by inclusion of SM data. It is assumed that smart meters measure consumption of individual domestic appliances, which enables detailed analysis of DR potential (i.e. flexibility) of the residential end-users. Following this and starting from the premise that shortterm active and reactive load forecast is available at a bulk supply point, the algorithm disaggregates the total load based on smart meters' data at a limited number of customers' premises.

Information about the composition of forecasted load can facilitate development of incentive-based DR programs. In other words, the network operator can develop a portfolio of appropriate actions to meet its operational objectives (e.g., reducing the cost of supply, increasing the reliability of the network) if the forecasted load composition displays insufficient amount of flexibility coming from demand side.

\section{RESIDENTIAL LOAD FLEXIBILITY}

Load decomposition (disaggregation) represents the process of assessing time-varying participation (in per unit or per cent) of different load categories within the total active or reactive load/demand. In order to decompose total load (active and reactive) of a number of houses where only some are monitored by smart meters, a two-step methodology is proposed. First, load disaggregation of the load monitored by smart meters is done based on monitored consumption of each appliance; second, disaggregation of the non-monitored load is performed using artificial neural networks (ANN). The accuracy of the approach is analyzed in order to assess the required coverage of a residential area with smart metering system that will obtain desired accuracy of load composition.

Load categories in this paper are defined as groups of appliances with similar voltage-dependent steady-state and dynamic load characteristics. Furthermore, load categories are divided into controllable and uncontrollable based on their potential to be shifted in time. According to the most commonly used appliances in residential sector in the UK [5], seven categories are recognized in this analysis and presented in Table 1. They are: single-phase constant torque induction motors (CTIM1), three-phase constant torque induction motors (CTIM3), single-phase quadratic torque induction motors (QTIM1), controllable resistive loads $\left(\mathrm{R}_{\mathrm{C}}\right)$, uncontrollable 
resistive loads $\left(\mathrm{R}_{\mathrm{UC}}\right)$, switch-mode power supply (SMPS) and Lighting.

Table 1. Load categories and corresponding types of appliances

\begin{tabular}{c|c|l}
\hline $\begin{array}{c}\text { Load } \\
\text { controllability }\end{array}$ & $\begin{array}{c}\text { Load } \\
\text { categories }\end{array}$ & \multicolumn{1}{c}{ Residential appliances } \\
\hline \hline \multirow{4}{*}{ Controllable } & CTIM1 & $\begin{array}{l}\text { Dish washer, tumble dryer, } \\
\text { washing machine, washer- } \\
\text { dryer, vacuum cleaner }\end{array}$ \\
\cline { 2 - 3 } & CTIM3 & Electrical space heating \\
\cline { 2 - 3 } & QTIM1 & $\begin{array}{l}\text { Chest freezer, fridge-freezer, } \\
\text { fridge, upright freezer }\end{array}$ \\
\cline { 2 - 3 } & $\mathrm{R}_{\mathrm{C}}$ & $\begin{array}{l}\text { Water heater, electrical } \\
\text { shower, storage heater }\end{array}$ \\
\cline { 2 - 3 } & $\mathrm{R}_{\mathrm{UC}}$ & $\begin{array}{l}\text { Iron, hob, oven } \\
\text { Uncontrollable }\end{array}$ \\
& SMPS & $\begin{array}{l}\text { Clock, telephone, high fidelity } \\
\text { (HiFi) appliances, } \\
\text { machine, PC, printer, TV, } \\
\text { VCR-DVD, } \\
\text { microwave }\end{array}$ \\
\hline
\end{tabular}

\section{METHODOLOGY}

The methodology for short term forecasting of demand composition developed in this study relies on three assumptions:

1) smart meters can measure consumption (real and reactive power) of individual appliances; as the load model [5] adopted for this methodology does not include reactive power, it is derived probabilistically, using the most probable from a range of possible values of power factor for each appliance;

2) the aggregation is performed considering 1000 endusers, where only part of them is monitored by smart meters;

3) measurements of total consumption (real and reactive power) at the primary substation point are available every minute and performed regularly, i.e. there are no missing data.

Considering these assumptions and taking into account that there is a short-term forecast of total active and reactive load at aggregation (bulk) point (provided by the aggregator or the distribution system operator), the load composition can be derived using adequately trained ANN. Three levels of SM coverage are compared in this paper: $20 \%, 50 \%$ and $80 \%$ coverage of 1000 customers considered at aggregation level.

The flowchart of the methodology is shown in Fig. 1. As an initial step before load decomposition process, the SM data is pre-processed and aggregated at data concentrator point (block $\{0\}$ ). Following the first assumption, part of the consumption which is monitored with smart meters can be decomposed by simply aggregating consumption of appliances belonging to the same category (block $\{2\}$ ) given in Table 1.

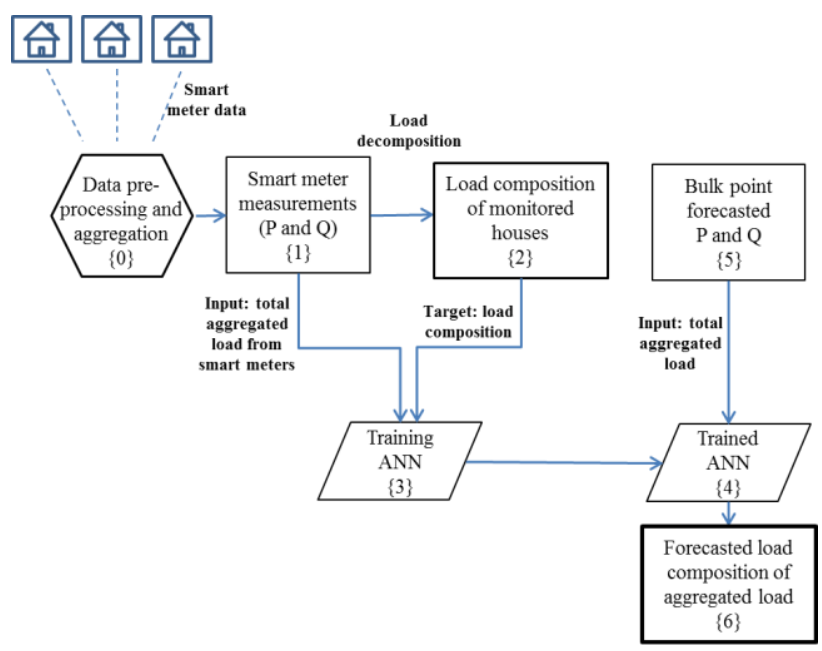

Figure 1. Flow chart for load disaggregation in case of smart metering system with partial coverage

Using monitored load data, a two-layer feed-forward ANN with back-propagation is used to decompose the total aggregated load. First, SM data is used for training the ANN using total monitored active and reactive power as input data and participation of the seven categories as the target data (block $\{3\}$ ). The training process is performed over one week data, which includes minutebased real and reactive power measurements, giving $7 \times 1440$ samples for each of the variables, presented in matrix form as follows:

$$
\text { Input }=\left[\begin{array}{ccccc}
P_{1} & \ldots & P_{i} & \ldots & P_{7 \times 1440} \\
Q_{1} & \ldots & Q_{i} & \ldots & Q_{7 \times 1440}
\end{array}\right]
$$

Target data, denoted as $W$, represents the calculated participation of each load category. If in a time step $i$, active load of category $j$ equals $P_{j i}$, then the participation $w_{j i}^{P}$ (in per unit) of that category is given as:

$$
w_{j i}^{P}=\frac{P_{j i}}{P_{i}}
$$

where $P_{i}$ is the total active load in a time step $i$. The following condition has to be fulfilled in each time step:

$$
\sum_{i=1}^{7} w_{j i}^{P}=1
$$

Target data can then be represented in a matrix form as follows:

$$
\text { Target }=\left[\begin{array}{ccc}
w_{1,1}^{P} & \cdots & w_{1,7 \times 1440}^{P} \\
w_{2,1}^{P} & \cdots & w_{2,7 \times 1440}^{P} \\
\vdots & \cdots & \vdots \\
w_{7,1}^{P} & \cdots & w_{7,7 \times 1440}^{P}
\end{array}\right]
$$

Once trained, the ANN (block $\{4\}$ ) uses total forecasted (day-ahead, in this case) active and reactive load at the bulk point (block $\{5\}$ ) as the input, giving its (forecasted) load composition as the output (block $\{6\}$ ). In case of reactive power, the participation of each category can be calculated based on obtained active load composition as follows: 
$w_{j i}^{Q}=\frac{Q_{j i}}{Q_{i}}=\frac{P_{j i} \tan \left(\varphi_{j i}\right)}{P_{i} \tan \left(\varphi_{i}\right)}=w_{j i}^{P} \frac{\tan \left(\varphi_{j i}\right)}{\tan \left(\varphi_{i}\right)}=w_{j i}^{P} \frac{\left(\frac{\sqrt{1-P F_{j i}^{2}}}{P F_{j i}}\right)}{\left(\frac{\sqrt{1-P F_{i}{ }^{2}}}{P F_{i}}\right)}$

where $\varphi_{j i}$ and $\varphi_{i}$ are phase angles of category $j$ and total load in time step $i$, respectively, and $P F_{j i}$ and $P F_{i}$ are corresponding power factors. Finally, load composition of both monitored and non-monitored houses is obtained.

\section{RESULTS}

In order to analyze the accuracy of the ANN proposed in this methodology, two types of errors are observed: Weighting Factor Error (WFE) and Absolute Weighting Factor Error (AWFE), where WFE is defined as follows:

$$
W F E_{c a t}=W F_{c a t, A N N}-W F_{c a t, \text { real }}
$$

$W F E_{\text {cat }}$ is the error (in p.u.) between the WFs obtained as the output of the ANN $\left(W F_{c a t, A N N}\right)$ and the real (original) WFs ( $W F_{\text {cat, real }}$ ) given for each category. The errors are presented in percentages with respect to the sum of all the weighting factors equal to $100 \%$ (total power) and given in a form of probability density function (PDF) and cumulative distribution function (CDF).

\section{Active load}

In order to assess the accuracy of load decomposition with different SM coverage using ANN, the case of $100 \%$ SM coverage, where all the end-users are monitored by smart meters, is given as the base case. As seen in Fig. $2 \mathrm{a}$, the most probable WFE for all the categories ranges between $-1 \%$ and $1 \%$, with $90^{\text {th }}$ percentile of AWFE not higher than 5\%, as seen in Fig. 2b. At the same time, Fig. $3 \mathrm{~b}$ shows that the most probable AWFE for controllable/uncontrollable load is less than $1 \%$, while the $90^{\text {th }}$ percentile of the error equals $5 \%$.
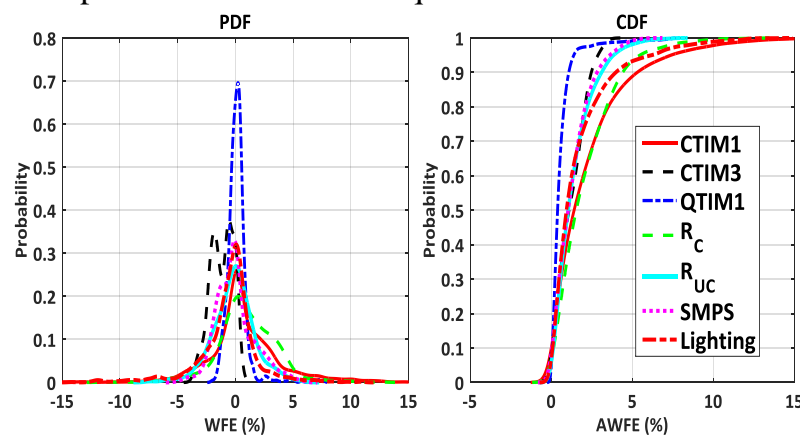

Figure 2. (a) PDF of WFE, and (b) CDF of AWFE for active load composition with $100 \%$ SM coverage

The cases with lower level of SM coverage will be compared based on the PDF of the WFE for load categories and PDF and CDF of the AWFE for controllable/uncontrollable load.
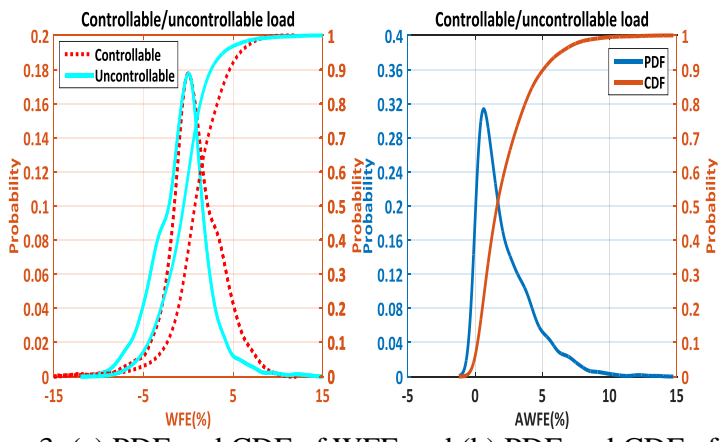

Figure 3. (a) PDF and CDF of WFE and (b) PDF and CDF of AWFE for active controllable/ uncontrollable load with $100 \%$ SM coverage

The case with $80 \%$ SM coverage shows accuracy in estimating the composition of the total aggregated load as high as in the base case, with the most probable WFE for all the categories between $\pm 1 \%$, as seen in Fig. 4 a. Fig. $4 \mathrm{~b}$ shows that the most probable AWFE for controllable/uncontrollable load estimation is around $1 \%$, while the $90^{\text {th }}$ percentile equals $5 \%$.
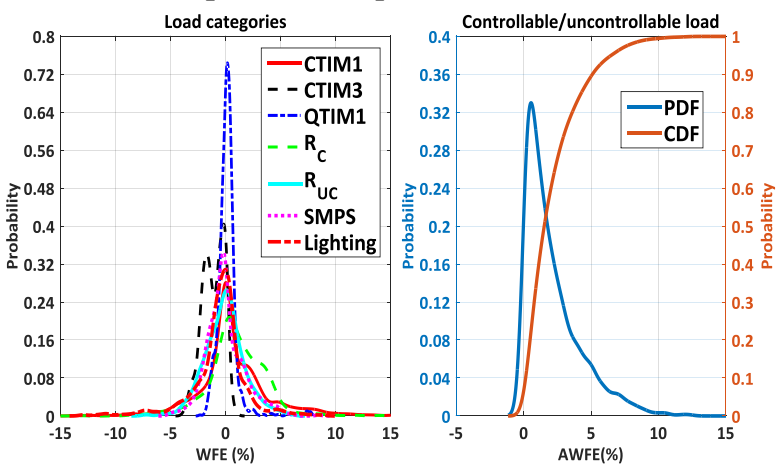

Figure 4. (a) PDF of WFE for load categories, and (b) $\mathrm{PDF} / \mathrm{CDF}$ of AWFE for controllable/uncontrollable load with $80 \%$ SM coverage

Going further, 50\% SM coverage, as shown in Fig. 5a and $5 \mathrm{~b}$, gives only slightly lower accuracy (with wider distribution of errors), than the case with $80 \%$ SM coverage, which is visible in the assessment of controllable/uncontrollable load.
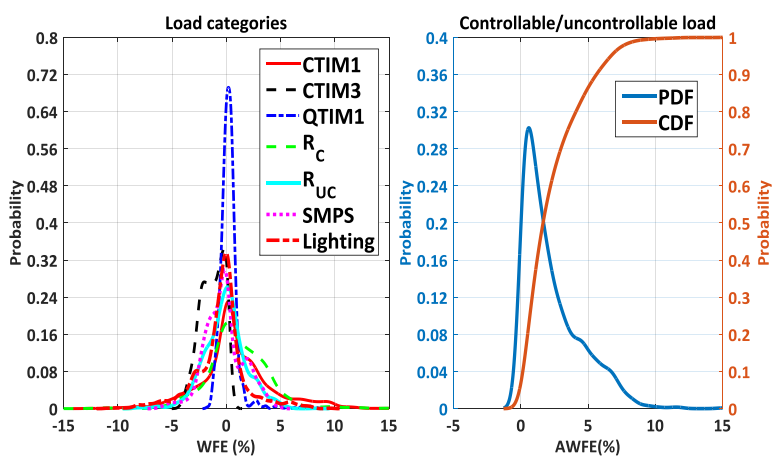

Figure 5. (a) PDF of WFE for load categories, and (b) $\mathrm{PDF} / \mathrm{CDF}$ of AWFE for controllable/uncontrollable load with $50 \%$ SM coverage

Decomposition of active load in case of $20 \%$ SM coverage is similarly accurate, with the only difference of some categories showing wider (uniform) distribution of errors, reaching $10 \%$ (Fig. 6a), while the controllable and 
uncontrollable load are still estimated with $90^{\text {th }}$ percentile of error around $6 \%$ (Fig. 6b).
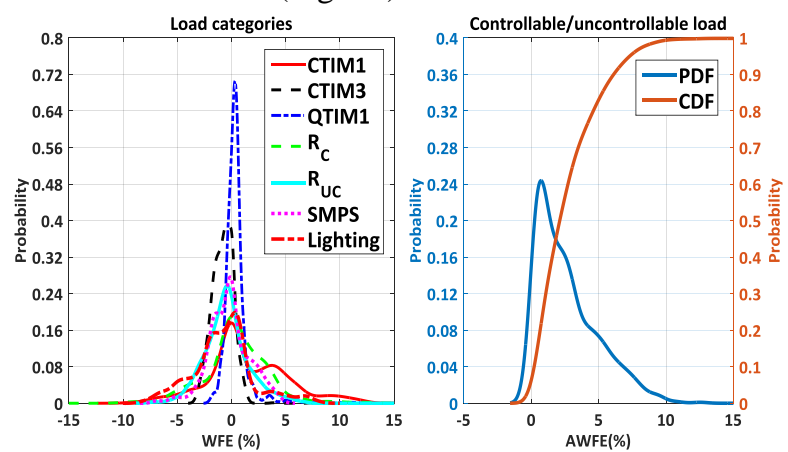

Figure 6. (a) PDF of WFE for load categories, and (b)

PDF/CDF of AWFE for controllable/uncontrollable load with $20 \%$ SM coverage

For illustration purposes, Fig. 7 presents the original composition of the aggregated load (from the adopted load model) and Fig. 8 presents the one from $20 \%$ SM coverage. It can be observed that the shares of load categories are visually fairly similar.

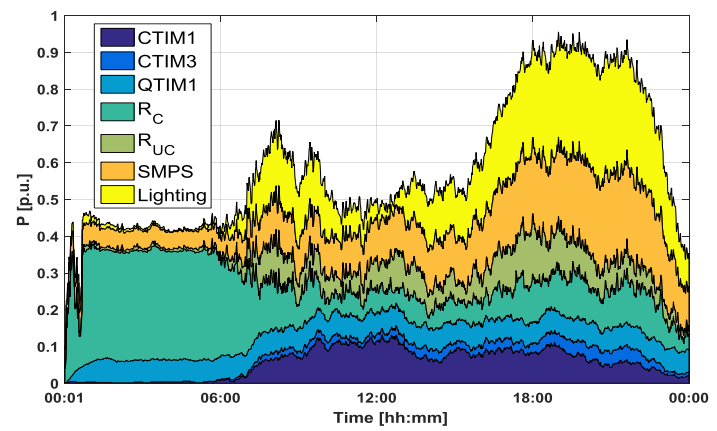

Figure 7. Original active load composition

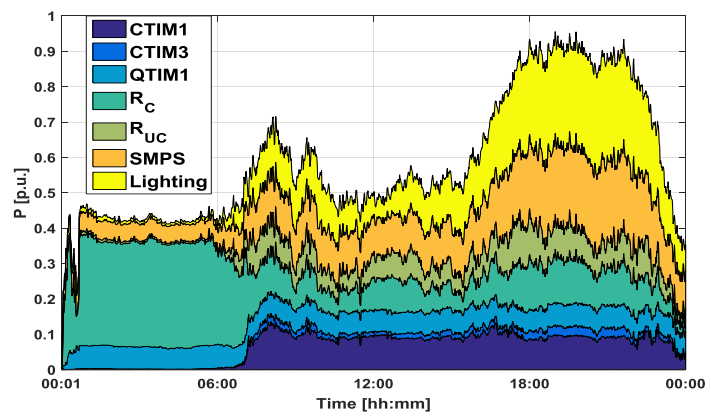

Figure 8. Active load composition with $20 \%$ SM coverage

\section{Reactive load}

The reactive load composition is calculated based on the ANN output for active load composition, using equation (5). As in the case of active power, SM coverage of $100 \%$ is taken as the base case. It can be seen from Fig. 9a that the distribution of WFE for load categories is wider, which means that the errors are higher than in case of active power (Fig. 2a). Also, the $90^{\text {th }}$ percentile of the error is not higher than $10 \%$ (Fig. 9b), which means that even with full SM coverage, the reactive load cannot be as accurately decomposed as the active one. Following this, although the most probable AWFE for controllable and uncontrollable load is around 1\%, as seen in Fig. 10b, $90^{\text {th }}$ percentile of the error is around $9 \%$.
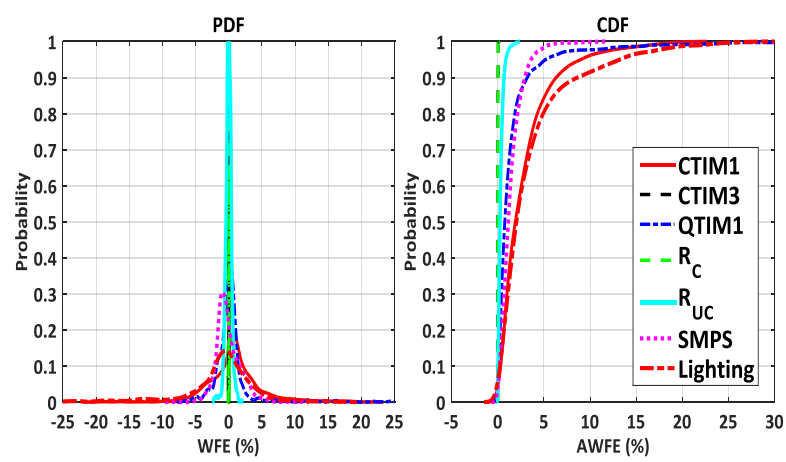

Figure 9. (a) PDF of WFE, and (b) CDF of AWFE for reactive load composition with $100 \%$ SM coverage
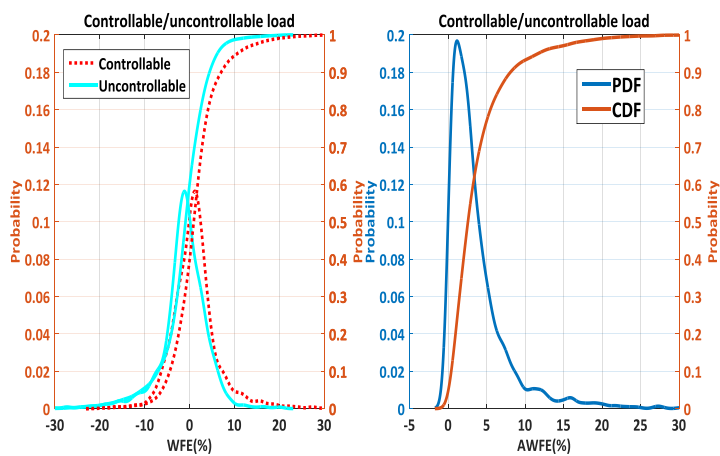

Figure 10. (a) PDF and CDF of WFE and (b) PDF and CDF of AWFE for controllable/ uncontrollable reactive load with $100 \%$ SM coverage

SM coverage of $80 \%$ gives similar accuracy for reactive load decomposition into categories and controllable and uncontrollable load as the base case, as shown in Fig. 11.
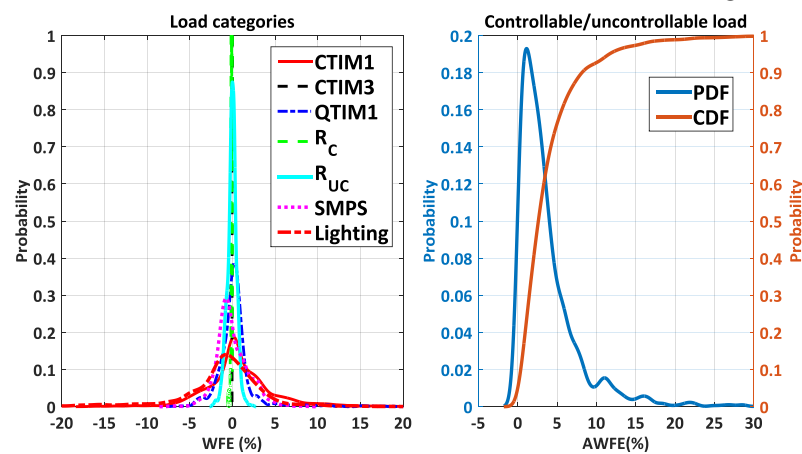

Figure 11. (a) PDF of WFE for load categories, and (b) $\mathrm{PDF} / \mathrm{CDF}$ of AWFE for controllable/uncontrollable reactive load with $80 \%$ SM coverage

With lower SM coverage, the accuracy slightly decreases. Fig. 12a shows that with 50\% SM coverage, the most probable WFE for load categories are still between $\pm 1 \%$, but the majority of errors reach $10 \%$. Therefore, the $90^{\text {th }}$ percentile of AWFE for controllable/uncontrollable load is around 9\%, as shown in Fig. 12b. 

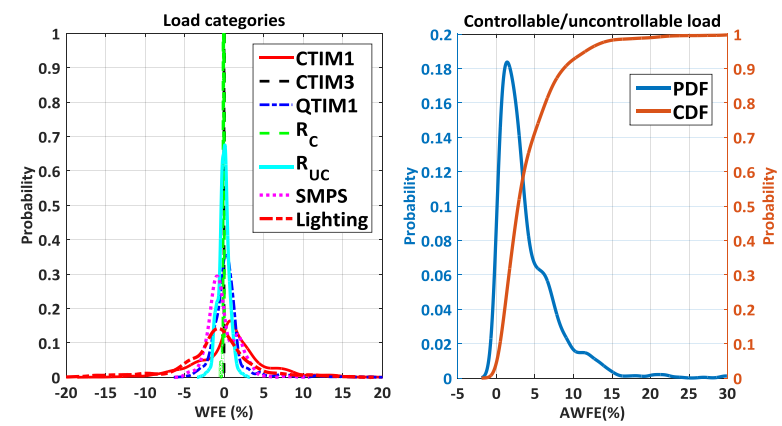

Figure 12. (a) PDF of WFE for load categories, and (b) $\mathrm{PDF} / \mathrm{CDF}$ of AWFE for controllable/uncontrollable reactive load with $50 \%$ SM coverage

Finally, in the case of $20 \%$ SM coverage, most load categories have errors more uniformly distributed between -10 and $10 \%$ (Fig. 13a), which is why the controllable and uncontrollable load are also estimated with $90^{\text {th }}$ percentile of AWFE around $10 \%$ (Fig. 13b).
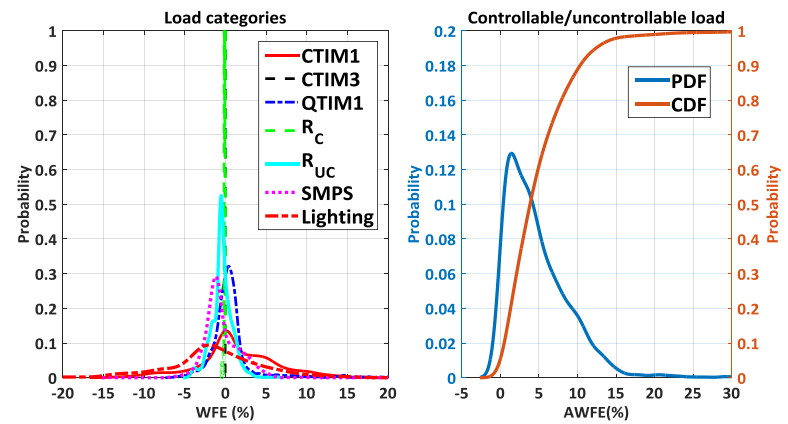

Figure 13 (a) PDF of WFE for load categories, and (b)

$\mathrm{PDF} / \mathrm{CDF}$ of AWFE for controllable/uncontrollable reactive load with $20 \%$ SM coverage

Again, for illustration purposes, Fig. 14 shows the original reactive load composition, while Fig. 15 shows the one obtained from $20 \%$ SM coverage - both show visual resemblance. Finally, as both active and reactive load decomposition show wider distribution of errors at the SM coverage of $20 \%, 50 \%$ is taken as the optimal coverage for overall load decomposition.

\section{CONCLUSION}

This paper presented methodology for load decomposition based on forecasted total active and reactive load at a bulk point and data from a limited number of smart meters. As the results show, the accuracy of reactive load decomposition has higher dependence on SM coverage than active load. 50\% SM coverage brings the optimal accuracy for overall (active and reactive) load decomposition, when compared to the base cases.

The methodology requires historical data on active and reactive power at the aggregation point, weather data (necessary for load forecasting) and per-appliance load data provided by available smart meters. Voltage measurement data is not necessary. Methodology will be further validated on real data from existing pilot sites with SM measurements of appliances' consumption.

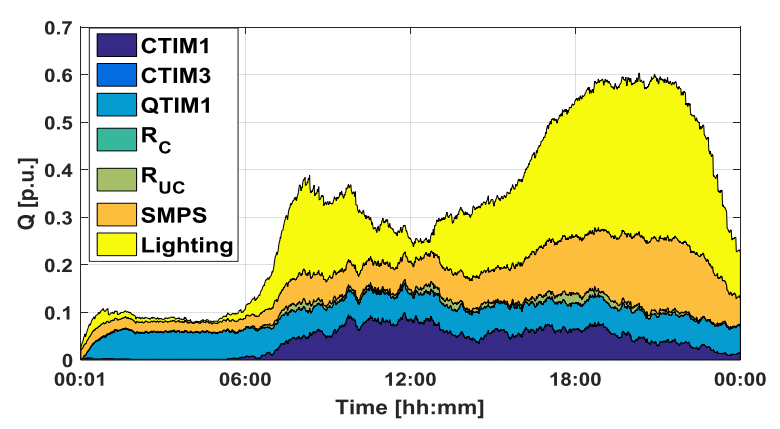

Figure 14. Original reactive load composition

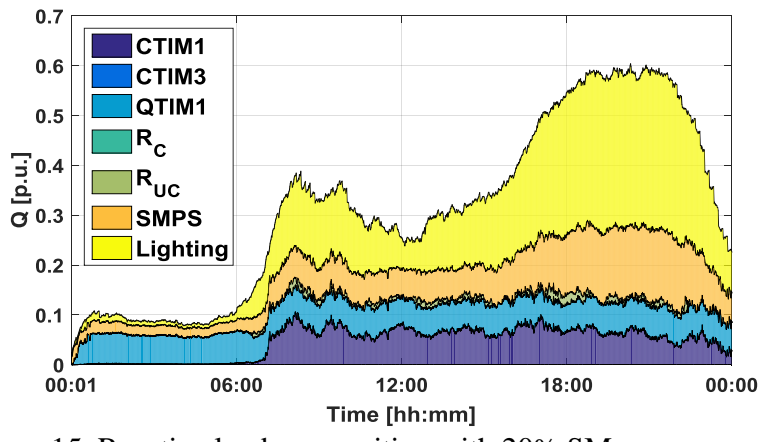

Figure 15. Reactive load composition with $20 \%$ SM coverage

\section{Acknowledgments}

This research is supported by EU Horizon 2020 project NOBEL GRID, contract number 646184

\section{REFERENCES}

[1] M. H. Albadi and E. F. El-Saadany, "A summary of demand response in electricity markets," Electric Power Systems Research, vol. 78, pp. 1989-1996, 2008.

[2] K. Samarakoon, J. Ekanayake, and N. Jenkins, "Reporting Available Demand Response," Smart Grid, IEEE Transactions on, vol. 4, pp. 18421851, 2013.

[3] "Digest of United Kingdom Energy Statistics 2015," Department of Energy and Climate Change,

[Online].Available:https://www.gov.uk/governm ent/uploads/system/uploads/attachment_data/file 1450302/DUKES 2015.pdf.

[4] L. Thomas and N. Jenkins, "Smart metering for the UK," 2012.

[5] I. Richardson, M. Thomson, D. Infield, and C. Clifford, "Domestic electricity use: A highresolution energy demand model," Energy and Buildings, vol. 42, pp. 1878-1887, 2010. 